should have been given; the abdomen promptly opened; the blood removed, the left appendages removed, the cavity cleansed, a drainage tube inserted, the incision closed, and Mrs. M. would have had at least two chances in three for recovery. But other counsel prevailed, the expectant treatment was adopted, the old teachings of Barnes on tubal gestation, and Thomas on hæmatocele, werre followed, and Mrs. M.'s life was a sacrifice to the ignorance and timidity of her physicians. It might be said that in her collapsed condition operation would have been fatal. Hot water should have been injected into the bowel, applied to the abdomen and extremities, the abdomen opened and the cavity irrigated with hot water, and she would have rallied from the shock. On the third day, at the beginning of the peritonitis, there was sufficient reaction, and then, if not before, the operation should have been done.

\section{THE MEDICAL JURISPRUDENCE OF MENTAL AND NERVOUS DISEASES.}

Read in the Section on Medical Furisprudence, at the Thirty. Eighth Annual Meeting of the American Medical Association, Fune, 1887 ,

BY S. V. CLEVENGER, M.D., or CHICAGo, ILL.

Insanity may be regarded from three prominent standpoints: the philosophical, the medical, and the legal. How soon there shall be consonance of views depends upon when there shall be general recognition of what is known about mental diseases.

Were the modern philosophical conclusions to prevail there would be no distinction between crime and insanity; society would simply adopt measures to protect itself against both as equally dependent upon faulty organization or function and more attention would be paid to circumventing the higher grade of criminals who seldom figure as such: the demagogue, the social hypocrite, and the unscrupulous millionaire gambler. It will be long before the populace comprehends that unjust judges, a Senate crowded with Neros and a feeble array of intelligence in the lower house can work more disaster than Bedlams and jails let loose; but the trend of enlightenment is toward mercy to the weak and protection against oppressors. Dr. Wm. D. Robinson, physician to the Eastern State Penitentiary of Pennsylvania, (in a paper read before the Philadelphia Neurological Society, March 28, I887) says that the major part of state prison offenses were the acts of men born mem. bers of the crime class of people. "They are one of the morbid excrescences from Society, and in progeny reproduce their peculiar kind. As the cancer cell lodged in a neighboring gland develops a growth identical in make up with its paternal source so the offspring of the crime class belie not their origin.

"These people very seldom reform, but in death end lives passed in crime and infamy. They have absolutely as little control over their natural inclinations to wrong doing as the confirmed periodical drunkard has over desisting from his spree.
"They really see very little moral wrong in their crimes - the crime with them being detection. They truly believe that the man who assists in their detection and aids in their being brought under the law is much worse than themselves.

"Crime is unquestionably a monomaniacal infatuation with them. Statistics, attested facts and direct attainable evidence clearly warrants this assertion. It is not an unusual case to have them acknowledge that they prefer the excitement of getting one dollar unlawfully to earning ten honestly."

Dr. Robinson goes on to show that neurotic diseases, syphilis and defects of the cranial contents exist among them. You are familiar with the disputations connected with the matter of responsibility in mental disease, and I will not trouble you with even a résumé thereof, but will ask your consideration of the philosophical view that criminality is madness.

It is not so long ago in the World's history, that sickness of all kinds was regarded as a diabolical possession and among some primitive people attempts were made by harsh treatment of the patient to scourge away the evil. When enough advance in reason had been made the sick were no longer held responsible for bodily ailments, but insanity was not regarded as depending upon any of the diseases to which mankind was subject, in fact it was not considered as a symptom of bodily disease at all.

Finally, this concession was made, and mental disorders are in many countries classed as sickness for which the sufferer is not held to account, though in Illinois a jury still determines the extent to which a person is guilty of insanity; or, if we admit that the law recognizes insanity as a disease then a lay jury merely makes a diagnosis.

Magnan and other pathologists, Crother and other clinicians, have demonstrated that many forms of inebriety depend upon defective organization. Criminality and drunkenness being the product of structural faultiness it is as sensible to "punish" the sick as the malefactor.

In sickness, insanity and criminality discipline is absolutely necessary; the delirium typhoid patient is prevented from leaving his bed and the rheumatic from eating unwholesome food. In the better class of asylums the insane are promoted to better wards and more privileges as an inducement to cultivate self-restraint, and this identical principle is operative to day in the Folsom (California) State prison where a graded system of fare is adopted for convicts according to their behavior.

That Society is as yet unwilling to identify crime with insanity, on the grounds of inexpediency, does not disprove the identity and is paralleled by the inability of our ancestors to accord irresponsibility in mental ailments.

Objections without number can readily be raised against a recognition of crime as insanity; one of the logical consequences of which would be the abolition of the penitentiary as a reformatory institution. In considering this aspect of the question I would deny that reformation of criminality was accomplished by such imprisonment, and claim that the convict 
who had served his term had merely graduated as a criminal, with of course here and there exceptions, which are such in spite of the system, the tendency of which is to confirm and to harden the convict. The protection of the community, for the time being, that the incarceration affords, is obtainable through any method of sequestration and is no argument in favor of the brutalizing punishments resorted to.

Legal gentlemen may laugh at this Utopian fancy, but let me tell them that penologists and alienists (who are not politicians) affirm that a large percentage of convicts are demonstrably insane from the standpoint of the layman, else why should there be a "crank department" in every such prison? I have known congenitally insane wretches to be forwarded to asylums after having been several years in prison with the statement that the lunatic had become so from the effects of imprisonment. Paretic dements, who in the beginning of their mental breakdown often commit larcenies or outrages against decency are condemned as criminals and soon die in a convulsion or after a maniacal outbreak. I have heard the question "What difference does it make, since death is inevitable, whether the patient die in the penitentiary or asylum?" The same might be urged in all cases in favor of an abolition of asylums and a return to the whipping, ducking and starvation methods of treating lunatics in recent centuries. Besides, ad hominem, would it make no difference to your family that the truth had been recognized and you had been permitted to die as insane instead of as a convicted thief? The "insanity dodge" does not seem to have availed among poverty stricken culprits when we can recall so many grossly insane patients converted into convicts. A pauper suffering from katatonia stabbed his wife in the most insanely brutal manner, exhibited all the peculiarities of that disease while in jail, but the political alienists and the jury forwarded him to the penitentiary where he was placed in the "crank department." A sixteen year old girl with hysterical insanity who attempted to poison her parents was also pronounced sane and sent to the same place; a paranoiac with petit mal who had shot two women for absurd reasons was given six years in the penitentiary. The illegality of this sentence appears in the nature of the offence if committed by a sane person justifying, under present laws, a life sentence, but the suspicion that he was not "well balanced" caused the term to be shortened. A life imprisonment in an insane asylum would have been more rational.

Where insanity is suspected in a criminal the European method of preceding trials by an expert commision examination saves a great expense to the State and avoids the farcicalities so common in our American courts in similar cases, but as our peculiar institutions would, in nine cases out of ten, foist ignorant politicians upon us as members of such a commission, scientific alienists are not inclined to enthusiastically favor a change from the present faulty methods of lunatic inquiry.

Many generations may come and go before the world can adjust itself to identify crime with insanity, but that eventually such a view will prevail appears to me to be inevitable as the outcome of progressive thought. When that time comes there will be no penitentiary, for the asylum will quarantine against all who cannot conform sufficiently to social requirements; there will, furthermore, be no practical politician, as we understand him to-day, for recognizing him as a member of the crime class his public treasury burglaries will be thwarted and the reason for his existence will cease.

Alienists are too busily engaged in trying to convince the lawyer and the public that there should be no distinction between medical and legal insanity to undertake greater tasks, and it is this constant endeavor of higher knowledge to adapt itself to the conceptions of the period that causes such a thing as medical jurisprudence to exist. It was formerly treason against God,king and common sense to deny witchcraft, all that could be done in defense was to prove the unfortunate not to be a witch. I am not so shallow as not to foresee that many considerations would arise under such an adjustment that would require a great revision of our statutes, but I believe the Code would be greatly shortened and that criminal lawyers would be few in number; the main ground for contention would be the fact of crime commission.

Polemics over accidental or designed acts would be abbreviated when the only object of the law would be to prevent a recurrence, and while Nature's failure to distinguish between a hand thrust deliberately or accidentally into the fire might not altogether be copied it could be thought of in disposing of the man who jokingly points an unloaded gun at another, for that species of imbecility is as deserving of regard as any other.

So much for the future; but as an evidence that enlightened views are beginning to prevail we may note that the Wisconsin Senate passed a bill to send convicted drunkards to insane asylums, in spite of the teachings of ecclesiasts that drunkenness is a crime and not a disease.

As however, in the present, responsibility is not to be discussed in court rooms from the philosophical side, it at least should be granted that the alienist is best able to consider the facts of insanity even from the legal and lay outlooks. At once, then, it should be known that insanity cannot be dealt with as one and indivisible any more than sickness in general. There are many kinds of insanity and a knowledge of their phenomena is requisite to an intelligent judgment. For example, take one of the circular or recurrent forms such as katatonia, where the patient may be melancholic, stupid, maniacal, and then apparently rational, alternately. Judge, jury and lawyers cannot pass upon such a case properly without a knowledge of these phases and as to whether the lunatic is or is not a katatoniac.

One with a head injury often becomes very intolerant of alcohol and upon occasion may commit some grave offense. These and multitudes of as well established facts should be duly held up to view.

There is such a malady as transitory frenzy, which may last hours or a less time and during which suicide 
or murder may be accomplished. I reported one State Legislature has been appealed to with regard to such case in which a poorly balanced female head, enacting some suitable punishment for attendants under large doses of some abortifacient, attempted who illy use, wound, or occasionally murder the into throw herself from a window and cut her arm ar- sane, but time is taken up by fisticuffs among the teries with scissors. Had the onslaught been made honorable members and calcimining self investigaupon some other person she would have had great tions covering alleged steals.

difficulty in proving her temporary insanity for it was of but brief duration.

Witness poor John McCullough, the actor, wandering about with his delusions of grandeur and nearly every other evidence of paretic dementia fully recognized as such by able alienists who were unwil. ling to advertise their judgment and suffer the abuse of medical ignorami, even though time would have sustained the verdict.

The German alienists more particularly have advanced psychiatry to a footing with many of the more exact provinces of medicine. This is no less a truth because the fact is not generally known and that practitioners are often found who, like Fordyce Barker, are capable of appearing as experts in toxicology, gynæcology, surgery, ophthalmology and psychiatry.

The olden dictum that the depths of one's attainments are inversely as their breadth, while needing some qualification, applies in such cases, for medicine has differentiated and developed beyond the possibility of any single person attaining proficiency in all. The shoemaker may as well attempt to dis. cuss the relative merits of Jurgensen and Waterbury watches as for the medical specialist in one line to pass judgment upon another.

If some legislative provision were made for insane criminals and the criminal insane as was suggested by Dr. Dewey, of the Kankakee Asylum, judges and juries might see their way clear to a more rational disposition of such cases as popular condemnation impels them to pronounce "sane but illy balanced "-_"not insane but a crank"-_responsible for his act but of a low grade intelligence."

Especially should medical men insist not only that physicians should be selected as superintendents of asylums but, if it is not asking too much, that such physicians should know something of insanity. Recently, in Chicago, lawyers were allowed to nomi nate candidates for judgeships from among them. selves. Why would it not be as well to permit physicians to select the heads of medical institutions, instead of relegating this power to saloon.keepers, gamblers and prize fighters, some of whom, at least, are indicted thieves and more are justifiably suspected to be.

At first glance it might seem advisable to compel asylum officials to keep full records of all cases admitted, and to have some more careful method for the receipt and discharge of lunatics, but as brains and scientific ability cannot be legislated into the heads of medical politicians the records kept by such a one would be valueless and the liberation of dangerous paretics can only be prevented by the asylum physician knowing a little about insanity, the recommendation that respectable alienists should be appointed to superintend asylums would cover the points better than the legislation named. The Illinois

Then as to the status of the expert in court: He is usually selected by one side instead of by the judge and theoretically is presumed to be unbiased. $\mathrm{He}$ is placed in a false position, for being the recipient of a fee from one side his allegiance would seem to be due to that side and were his testimony harmful thereto he would, with some show of justice, be considered as having betrayed his trust.

There seems to be but one honest position for him to assume: that of a partisan who may coach the lawyer who engages him. If he can conscientiously, in addition to this, go upon the stand as an expert his convictions should be freely expressed and the lawyer should take his chances with such testimony just as with that of any other witness whom he calls.

Ray's suggestions are good:

I. That the expert should be asked if he gave his entire time to the study and practice of one branch of medicine, and if that branch was psychiatry.

2. That the expert opinion should be rendered in writing which would cause legal trickery to be harm. less.

These suggestions apply equally well to neurological cases which are mainly actions against corporations for spinal injuries wherein Ericson figures largely for the plaintiff against Page for the defendant. In a disorder that presents such a preponderance of subjective symptoms as spinal concussion, and in all other cases where simulation might be alleged as in paralysis, contractures, etc., the value of faradic and galvanic tests of muscles and nerves should be more fully appreciated, especially since with the milliamperemeter and Erb's electrical charts we have the means of graphically presenting the conditions ascertained in such a manner that the jury may readily comprehend.

\section{THE USE OF THE CURETTE AND INTRA-UTERINE DOUCHE AFTER LABOR AT TERM.}

Read before the Chicago Medical Society, September 19,8887 . BY J. SUYDAM KNOX, M.D., of chicago, iIL.

I think it will pass unquestioned that the sole object of washing out the uterine cavity, or of using the curette within it, post-partum, is for antiseptic purposes. Septicamia or putrid absorption is possible during the puerperium of every woman. If, therefore, these operations are perfectly harmless, they should be freely performed as a prophylactic measure, and should be heartily endorsed by obstetricians.

If, again, the uterine cavity be the common origin of the septic and inflammatory accidents of the lying-in, again should the curette and the intra-uterine douche be used at the first signals of such abnormal disturbance. 